\title{
Childhood obesity: a pandemic of the twenty-first century
}

\author{
E Malecka-Tendera ${ }^{1}$ and A Mazur ${ }^{2}$ \\ ${ }^{1}$ Department of Paediatric Endocrinology and Diabetes, Silesian Medical University, Katowice, Poland and ${ }^{2}$ Institute of \\ Physiotherapy, University of Rzeszow, Rzeszow, Poland
}

Background: The researchers and clinicians need to gain a better understanding of the social and environmental contexts by which childhood obesity is becoming a growing problem of twenty-first century and develop more efficacious methods of prevention and treatment.

Methods: Summary of the actions and achievements of the European Childhood Obesity Group (ECOG) since its foundation in 1991 until the 16th anniversary. Review of the sessions of the 16th ECOG workshop devoted to epidemiology, prevention, risk factors, comorbidities and treatment of childhood and adolescent obesity.

Results: Meta-analysis of epidemiological data on childhood obesity in Europe underscores an urgent need of preventive actions in which general practitioners may play an important role. Media should get actively involved in promotion of healthy lifestyle. Metabolic syndrome, non-alcoholic steatohepatitis, diabetes type 2 and sleep apnoea syndrome are becoming more common in obese adolescents. In morbid obesity with severe comorbidities, more aggressive ways of treatment may be considered.

Conclusions: European Childhood Obesity Group members should get actively involved into targeted prevention and intervention project to promote healthy lifestyle and successful weight control.

International Journal of Obesity (2006) 30, S1-S3. doi:10.1038/sj.ijo.0803367

Keywords: paediatric obesity; epidemiology; prevention; comorbidities; treatment

\section{Introduction}

Obesity - a pandemic of the twenty-first century - is affecting more than a billion people worldwide. Two to three times more people are overweight. Unfortunately, this growing problem is also concerning children of various ages. Data from the International Obesity Task Force ${ }^{1}$ indicate that 22 million children under the age of 5 are obese or overweight.

In the face of a growing problem of childhood obesity in 1991, a group of physicians established the European Childhood Obesity Group (ECOG). Some of its founding members were Elisabeth Poskitt (UK), Walter Burniat (Belgium), Carl Zwiauer (Austria), Margherita Caroli and Claudio Maffeis (Italy), Denes Molnar (Hungary) and Marie-Laure Frelut (France), all deeply involved in the research on obesity in children and adolescents. Since that time, ECOG has grown not only with respect of number of members but most of all with respect of its position, becoming the most important European association dealing with different aspects of childhood overweight. Group members have published in collaboration numerous important papers

Correspondence: Professor E Malecka-Tendera, Department of Paediatric Endocrinology and Diabetes, Silesian Medical University, Katowice 40 675, Poland.

E-mail: etendera@slam.katowice.pl devoted to epidemiology, risk factors, complications, prevention and treatment of obesity in children. The first article dealing with definition of childhood obesity based on body mass index $(\mathrm{BMI})^{2}$ was a statement of ECOG members participating in the third Workshop in St Poelten, Austria, 1993. In 1999, a project of a collaborative study on the prevalence of obesity was established. ${ }^{3}$ Two studies, based on the same protocol, were conducted simultaneously in France and in Poland and their results were published in $2002^{4}$ and 2005. In 2002, a book entitled 'Child and Adolescent Obesity' resulted from the common work of the entire Group. ${ }^{6}$ Metaanalysis of childhood obesity prevalence and meta-analysis of diabetes type 2 prevalence in European children were made possible owing to the data provided mostly by the ECOG members. Their results were published in $2003^{7}$ and $2005 .{ }^{8}$ In 2004, proceedings of the 13th ECOG workshop were printed in another book - 'Childhood Obesity from Basic Sciences to Public Health'. ${ }^{9}$ Since several years, abstracts and full papers of consecutive workshops have been published in supplements of International Journal of Obesity. Angelo Pietrobelli, a member of the ECOG, became a Paediatric Associate Editor of this Journal.

This year, ECOG is approaching its maturity at the 16th workshop in Rzeszow, Poland. Over 100 abstracts have been submitted by the authors from 27 countries located on five continents. Several important topics will be submitted for discussion and lot of experience is going to be exchanged. 


\section{S2}

\section{Epidemiology}

Over the past 30 years, the prevalence of overweight and obesity in children has been increasing dramatically in most of the developed countries. There has been a trend towards its increasing prevalence in developing countries, and in some parts of Africa, the problem of childhood overweight has replaced malnutrition. ${ }^{10}$

There are strong national differences in prevalence of childhood obesity. Approximately, 30\% of children in the United States are overweight or obese. ${ }^{11}$ In Europe, a review of 21 surveys indicated generally lower levels of overweight among children from the countries of central and eastern part of the continent compared to the countries surrounding the Mediterranean. ${ }^{7}$ In Italy and Spain, over $30 \%$ of 7 - to 11 year-old children were obese or overweight, whereas in Denmark or the Czech Republic, the prevalence of overweight in the same age group was only $12 \%$. In children $14-$ 17 years old, prevalence of overweight including obesity was lower than $22 \%$, regardless of the country.

\section{Risk factors}

This increased incidence of childhood obesity is multifactorial as it cannot be blamed on genetics or environment alone. It is obviously not possible for the gene pool to change in one or two generations. Molecular genetic abnormalities can presently account for less than $5 \%$ of obese individuals. Obesity is a clinical feature of some rare genetic syndromes. The most common is Prader-Willi syndrome caused by the deletion of the q11-q13 fragment of the paternal chromosome 15 . Severe obesity occurs in early childhood and is resistant to diet.

Excessive body mass is a characteristic clinical sign in children with Bardet-Biedl or Down's syndromes.

Genes may play a permissive role in fat storing paired with sedentary lifestyle and energy dense diet. Maternal and paternal obesity significantly increase the risk of overweight in their children as well as the maintenance of increased body fat mass into adulthood. Childhood obesity is also associated with lower family socioeconomic status. ${ }^{12}$ Furthermore, parents commonly do not perceive their children as overweight or do not consider obesity as a risk factor of impaired physical health. ${ }^{13}$

During the past two decades, there was a dramatic change in the lifestyle that also affected the young generation. The increasing amount of time, instead of playing outside, children spend watching television or playing computer games. This habit is related with parents' perception of the neighbourhood as unsafe and reluctance to allow their children to go out to play. ${ }^{14}$ Television watching is directly linked to childhood obesity not only due to the inactivity but also due to the energy dense food advertising. ${ }^{15}$ Some studies demonstrated that children's food preferences can be influenced even by 30-s exposures to the TV commercials. ${ }^{16}$ Fast food is also marketed to children through toys and social events.

\section{Complications}

Childhood overweight is associated with several adverse consequences. Obese children are at high risk for adult obesity and obesity in adults leads to increased morbidity. However, as the incidence of childhood obesity has increased, paediatricians face the health problems that were restricted formerly to the adult patients.

Type 2 diabetes (T2DM) is now diagnosed in about $20 \%$ of pubertal children referred to diabetic clinics in the US. ${ }^{17}$ In Europe, although less common, it is present in ethnic minorities but also reported in obese Caucasian adolescents, mostly girls with positive family history for T2DM. ${ }^{8}$

Metabolic syndrome (MS) is being identified in up to $30 \%$ of obese children. Males of Hispanic origin are at the highest risk; however, abdominal obesity increases the risk of MS in all overweight adolescents. ${ }^{18}$ Children who have components of MS tend to continue with them into adulthood. There are no definite criteria of the MS for paediatric age group and very limited paediatric reference values for waist circumference in Caucasian children. ${ }^{19}$

Non-alcoholic steatohepatitis is an increasing clinical problem in obese children and adolescents. ${ }^{20}$ It is a clinicalpathological condition in which the liver biopsy shows the signs of steatosis, inflammation and hepatocyte destruction. Its natural history may have a benign course without severe liver function impairment or in rare cases - progression to cirrhosis. $^{20-22}$ Most children are asymptomatic and a clinical challenge is to identify those at risk for progression to cirrhosis as the candidates for potential therapy.

Obstructive sleep apnoea (OSA) syndrome is strongly associated with obesity. In patients with OSA, sleep architecture is disrupted with several obstructive episodes and arousal every night. Severely obese children are 4-6 times more likely to develop OSA than their lean peers. ${ }^{23}$

\section{Prevention}

In 2003, the American Academy of Paediatrics issued a policy statement on prevention of paediatric obesity and overweight. ${ }^{24}$ It states that paediatricians should recognize children at risk for obesity, calculate and plot BMI to identify weight gain and monitor obesity related comorbidities. Other strategies should be breastfeeding encouragement, healthy eating habits and physical activity promotion as well as limitation of TV viewing.

Prevention of obesity in children should be the first line of treatment. However, it is doubtful whether obesity is preventable using currently available intervention strategies. Data from randomized trials to support any particular 
strategy to prevent the development of overweight in children are lacking.

\section{Treatment}

Basic treatment interventions are based on lifestyle changes: diet modification and increased physical activity. Diet should be restricted to produce mild negative energy balance. Soft sugary drinks should be replaced with water. Saturated fats, salty snacks and high glycaemic foods should be reduced and consumption of fruit and vegetables increased. Exercise should be tailored to the child's fitness ability. It is essential to change sedentary behaviour by restricting TV viewing, video games and internet surfing hours. Diet and exercise regimens usually are effective for short-term treatment but long-term effects have been disappointing owing to the noncompliance and high dropout rates. ${ }^{25}$

Aggressive approaches to treatment for severely overweight children and adolescents include restrictive hypocaloric diets, drug therapy and bariatric surgery. They should be considered only in morbidly obese patients with severe comorbidities. Very low calorie diets result in rapid weight loss but should not be used in long-term treatment and require physicians monitoring. Currently approved drugs for management of obesity in adolescents ( $>16$ years old) are sibutramine and orlistat. Metformin, an insulin sensitizer, is administered to children with T2DM, but in some trials, it reduced BMI zscore even in the absence of dietary intervention. ${ }^{26}$

Bariatric surgery may be indicated in selected subjects with extreme obesity and severe comorbidities. ${ }^{27}$ Potential candidates for this type of treatment should be referred to centres with multidisciplinary weight management teams. Patients and their families should be aware of possible risks and side effects of individual bariatric surgical procedures and fully understand that it is an effective weight loss tool only when patients comply with recommended dietary and physical activity regimen.

All the above-mentioned topics are going to be a matter of discussion during the 16th ECOG workshop. The participants are aware that it is absolutely necessary for the researchers and clinicians to gain a better understanding of the social and environmental contexts by which childhood obesity is becoming a pandemic of twenty-first century. Further knowledge in these fields will certainly give us more opportunities to develop efficacious actions for prevention and treatment of obesity and its complications.

\section{References}

1 Deitel M. The International Obesity Task Force and 'globality'. Obes Surg 2003; 12: 613-614.

2 Poskitt EME. Defining childhood obesity: the relative body mass index (BMI). Acta Paediatr 1995; 85: 961-963.

3 Lehingue Y. The European Childhood Obesity Group (ECOG) Project: the European collaborative study on the prevalence of obesity in children. Am J Clin Nutr 1999; 70: 1665-1685.
4 Rolland-Cachera MF, Castetbon K, Arnault N, Bellisle F, Romano $\mathrm{MC}$, Lehingue $\mathrm{Y}$ et al. Body mass index in 7-9-y-old French children: frequency of obesity, overweight and thinness. Int J Obes Relat Metab Disord 2002; 26: 1610-1616.

5 Malecka-Tendera E, Klimek K, Matusik P, Olszanecka-Glinianowicz M, Lehingue Y. Obesity and overweight prevalence in Polish 7-9 year old children. Obes Res 2005; 13: 964-968.

6 Burniat W, Cole T, Lissau I, Poskitt E. Child and Adolescent Obesity. Cambridge University Press: Cambridge, 2002.

7 Lobstein T, Frelut ML. Prevalence of overweight among children in Europe. Obes Rev 2003; 4: 195-200.

8 Malecka-Tendera E, Erhardt E, Molnar D. Type 2 diabetes mellitus in European children and adolescents. Acta Paediatr 2005; 94: 543-546.

9 Caroli MA, Chandra RK, Frelut ML. Childhood Obesity: From Basic Sciences to Public Health. Giuseppe de Nicola-Napoli, 2004.

10 Martorelli R, Kettel Khan L, Hughes ML, Grummer-Strawn LM. Overweight and obesity in preschool children from developing countries. Int J Obes Relat Metab Disord 2000; 24: 959-967.

11 Fox R. Overweight children. Circulation 2003; 108: e9071 (Editorial).

12 Reilly JJ, Armstrong J, Dorosty AR, Emmett P, Ness A, Rogers I et al. Early risk factors for obesity in childhood: cohort study. $B M$ ) 2005; 330: 1357-1359.

13 Carnell S, Edwards C, Croker H, Boniface D, Wardle J. Parental perception of overweight in 3-5 y old. Int J Obes Relat Metab Disord 2005; 29: 351-355.

14 Lumeng JC, Appugliese D, Cabral HJ, Bradley RH, Zuckerman B. Neighbour safety and overweight status in children. Arch Pediatr Med 2006; 160: 25-31.

15 Kaur H, Choi WS, Mayo MS, Harris KJ. Duration of television watching is associated with increased body mass index. J Pediatr 2003; 143: 506-511.

16 Wilson N, Quigley R, Mansoor O. Food ads on TV: a health hazard for children? Aust NZ J Public Health 1999; 23: 647-650.

17 Arslanian S. Type 2 diabetes in children: clinical aspects and risk factors. Horm Res 2002; 57 (Suppl 1): 19-28.

18 Cook S, Weitzman M, Auinger P, Nguyen M, Dietz WH. Prevalence of a metabolic syndrome phenotype in adolescents: findings from the third NHANES, 1988-94. Arch Pediatr Adolesc Med 2003; 157: 821-827.

19 McCarthy HD, Jarrett KV, Craley HF. The development of waist circumference percentiles in British children aged 5.0-16.9 y. Eur J Clin Nutr 2001; 55: 902-907.

20 Molleston JP, White F, Teckman J. Obese children with steatohepatitis can develop cirrhosis in childhood. Am J Gastroenterol 2002; 97: 2460-2462.

21 Marion AW, Baker AJ, Dhawan A. Fatty liver disease in children. Arch Dis Child 2004; 89: 648-653.

22 Schimmer JB, Deutsch R, Rauch JB, Behling C, Newbury R, Lavine JE. Obesity, insulin resistance and other clinicopathological correlates of pediatric non-alcoholic fatty liver disease. $J$ Pediatr 2003; 143: 500-505.

23 Young T, Peppard PE, Gotlieb DJ. Epidemiology of obstructive sleep apnea: a population health perspective. Am J Respir Crit Care Med 2002; 165: 1217-1239.

24 American Academy of Pediatrics. Overweight and Obesity: AAP Recommendations. AAP: Elk Grove Village, IL, 2003, www.aap.org?obesity/recommendations.htm.

25 Pinelli L, Elerdini N, Faith MS, Agnello D, Ambruzzi A, Simone M et al. Childhood obesity: results of a multicenter study of obesity treatment in Italy. J Pediatr Endocrinol Metab 1999; 12 (Suppl. 3): 795-799.

26 Freemark M, Bursey D. The effects of metformin on body mass index and glucose tolerance in obese adolescents with fasting hyperinsulinemia and family history of type 2 diabetes. Pediatrics 2001; 107: E55.

27 Inge TH, Krebs NF, Garcia VF, Skelton JA, Guice KS, Strauss RS et al. Bariatric surgery for severely overweight adolescents: concerns and recommendations. Pediatrics 2004; 114: 217-223. 